\title{
Strengthening healthcare providers' skills to improve HIV services for MSM in Kenya
}

\author{
Elise M. van der Elst ${ }^{a, b}$, Evans Gichuru ${ }^{a}$, Nicolas Muraguri ${ }^{c}$, \\ Helgar Musyoki ${ }^{d}$, Murugi Micheni ${ }^{a}$, Bernadette Kombo ${ }^{a}$, \\ Adrian D. Smith ${ }^{\mathrm{e}}$, Susan M. Graham ${ }^{\mathrm{f}}$, Eduard J. Sanders ${ }^{\mathrm{a}, \mathrm{b}, \mathrm{g}}$ \\ and Don Operario ${ }^{\mathrm{h}}$
}

AIDS 2015, 29 (Suppl 3):S237-S240

\begin{abstract}
Research on HIV burden and determinants of HIV risks among MSM in sub-Saharan Africa is now considerable [1]. A meta-analysis of 51 surveys conducted between 2005 and 2013 estimated 18.7\% HIV prevalence among MSM, a disproportionately large contribution to the HIV epidemic in sub-Saharan Africa [2,3]. Targeted interventions for MSM could significantly decrease HIV transmission, not only among MSM but also on a population level [4,5]. However, anal intercourse in African societies remains highly stigmatized and HIV public health messaging is still unfocused [6]. Compilation of data on testing behaviour among African MSM derives mostly from studies centred among urban and sex worker MSM $[7,8]$ and indicates that legal policy, social inequality, and inadequate training of healthcare providers (HCPs) discourage MSM from seeking HIV prevention and treatment [9-13]. Addressing HIV and other health needs among MSM in this region cannot be met through the healthcare sector alone. Rigorous structural efforts promoting a skilled healthcare labour force, and community sensitization to protect against unfair treatment will improve the provision of effective and ethical health services for African MSM [11,12,14-21].
\end{abstract}

Efforts to improve access to and healthcare services for Kenyan MSM in the context of HIV research started by our team in coastal Kenya, in 2005. In collaboration with the Kenya Medical Research Institute-Wellcome Trust Research Programme and supported by the International AIDS Vaccine Initiative, Kenyan MSM have been studied in a longitudinal cohort with the aim to prepare populations for HIV-1 vaccine efficacy trials and analyse the immune and viral profiles of individuals who have seroconverted to inform the design of potential HIV-1 vaccines [22]. Although care has been provided in the context of research, this project was the first in Kenya to actively mobilize, test, and link HIV-infected MSM to comprehensive care, including antiretroviral therapy (ART) [3]. HIV-positive men are currently followed in a longitudinal cohort in parallel with the vaccine feasibility study [23-26].

The study clinic initially provided a safe haven wherein MSM study volunteers felt protected and understood by counsellors and clinicians. A major shift took place after an antigay campaign resulted in an attack on the Kenya Medical Research Institute-International AIDS Vaccine Initiative research clinic in Mtwapa in 2010 [14]. In light of HCPs' potential role to mitigate this societal aggression, we introduced a sensitization programme to provide information on male same-sex behaviour and address the initially deeply held attitudes and beliefs among $74 \mathrm{HCPs}$ in the 49 ART-providing healthcare facilities in the Kenyan Coast $[17,27]$. This sensitization programme is freely available on www.marps-africa.org.

In African communities, HCPs hold strategic positions, not only because of their social legitimacy and robust presence in public institutions, but also because of the critical role they play implementing ethical principles in their communities. Initial evaluation of the MSM sensitization programme suggested short-term improvements in knowledge and reductions in homophobia 3 months postintervention [17]. Rollout of the MSM

\footnotetext{
${ }^{a}$ Kenya Medical Research Institute - Wellcome Trust Research Programme, Kilifi, Kenya, ${ }^{b}$ Department of Global Health, Academic Medical Centre, University of Amsterdam, Amsterdam, the Netherlands, ${ }^{\mathrm{c} M i n i s t r y}$ of Health, ${ }^{\mathrm{d}} \mathrm{National}$ AIDS and STI Control Programme, Nairobi, Kenya, ${ }^{\mathrm{e}}$ Nuffield Department of Population Health, University of Oxford, Oxford, UK, ${ }^{\mathrm{f}}$ Departments of Medicine, Global Health, and Epidemiology, University of Washington, Seattle, Washington, USA, ${ }^{\mathrm{g} N u f f i e l d ~ D e p a r t m e n t ~ o f ~}$ Medicine, University of Oxford, Oxford, UK, and h'School of Public Health, Brown University, Providence, Rhode Island, USA. Correspondence to Elise M. van der Elst, Kenya Medical Research Institute, Wellcome Trust Research Programme, PO Box 230, Kilifi, Kenya.
}

Tel: +254 41 7522133; fax: +254 41 7522390; e-mail: EvanderElst@kemri-wellcome.org

DOI:10.1097/QAD.0000000000000882

ISSN 0269-9370 Copyright $(\subset) 2015$ Wolters Kluwer Health, Inc. All rights reserved. This is an open access article distributed under the Creative Commons Attribution License 4.0, which permits unrestricted use, distribution, and reproduction in any medium, provided 
sensitization training across the HIV health sector in Kenya has resulted in over 1200 trained HCPs to date. Yet, a 2-year follow-up analysis of the initially 74 trained HCPs revealed challenges in sustaining the effects (van der Elst EM, Kombe B, Gixhuru E, Omar A, Musyoki H, Graham SM, et al. The green shoots of a novel training programme: progress and identified key actions to providing services to MSM at Kenyan health facilities, 2015, in preparation). Despite HCPs' enduring personal commitment, providing fair and appropriate services, retention of new attitudes and practices in the presence of pervasive institutional and societal discrimination remained difficult. Trained HCPs described secondary stigma from their coworkers and managers as pressure to conform to the standards of Kenyan society and their health institutions, which continued to view male samesex behaviour as immoral and illegal [27].

Experiences of the trained HCPs confirmed that public healthcare is an innately social process. Profession standards and cultural values demonstrated how power within society affects power within healthcare settings. For HCPs to successfully challenge these power structures that prevent change, they need to be self-consciously aware of the way in which their own powerful position either facilitates or inhibits MSM coming forward for HIV healthcare.

Interestingly, 10 years after the first MSM enrolled for an HIV-1 vaccine feasibility study in Mtwapa, biomedical research will soon involve approximately 2000 MSM in either ongoing care or research programmes in Kenya. These care and research programmes will enroll 100 MSM in the HIV Prevention Trials Network 075 multicenter observational study in Kisumu starting in 2015, 700 MSM to the Anza Mapema Test and Treat study in Kisumu, also starting in 2015, and continue to support 1000 MSM currently accessing care and support at the Sex Worker Outreach Programme in Nairobi and close to 200 MSM in Mtwapa. As a result, Kenyan and international researchers have formed an MSM health research consortium in 2014. The aspirations of this consortium include the development of new, innovative biomedical and behavioural research together with the goal of informing and assisting the Kenya Ministry of Health as well as international agencies to inform policy and practice and improve health outcomes for MSM in Kenya and elsewhere.

Key epidemiological and social science studies have raised awareness of MSM to policy makers at local and national levels and, together with Kenya's 'Mode of Transmission Analysis' [28], have highlighted MSM as a key population in the national HIV epidemic, resulting in the inclusion of MSM in Kenya's AIDS Strategic Framework [29]. Another report by the Kenyan National AIDS Control Council proposes a suite of interventions including behaviour modification, early ART, preexposure prophylaxis $(\operatorname{PrEP})$, and male circumcision that can be tailored to different risk groups [30].

Although MSM receive strong prioritization in policy documents and in some research and care settings in Kenya, what is actually urgently needed is a much broader emphasis on sensitization training of a professional cadre of HCPs (both in-service and preservice). Although decriminalization of same-sex behaviour is beyond the Ministry of Health's mandate, it is feasible that the Ministry could support and advance HCPs' feelings of empowerment and legitimacy to provide nondiscriminatory services to MSM.

Greater inclusion of MSM in health services is also warranted given the role of PrEP as a strategy for HIV prevention. Modelling by WHO estimates that, worldwide, $20-25 \%$ reduction in HIV incidence in MSM could be achieved through PrEP, averting up to 1 million new infections over 10 years [31]. PrEP has shown efficacy in several trials and is up to $92 \%$ effective against HIV transmission, but if medication adherence is lacking, PrEP effectiveness will steeply drop [32]. Although it is hoped that PrEP will be provided to MSM in Kenya, successful implementation will depend on qualified HCPs whose care for PrEP users will be fundamental to the success to this prevention strategy.

In the absence of a free PrEP programme for MSM, how will HIV-1 infections be prevented in this group? Targeting MSM and other key populations for immediate ART will confer individual benefits and will likely reduce onward transmission [33]. HIV and health are not simply biomedical issues but social and political phenomena, which require huge efforts to change in society. In Kenya, adoption of the MSM sensitization training in all medical training colleges and by professional associations, including the Kenya Medical Association, National Nurses Association of Kenya, and Kenya Association of Professional Counsellors, is a first step sending a strong message in the context of health equity. Although inclusion of the MSM sensitization training in health education alone will be insufficient to close the gap in the broader context of cultural, religious, and political antiMSM sentiment, it may, with careful planning and coordination, achieve a paradigmatic shift in HIV healthcare and become part of a broader social evolution. HCPs across Kenya and beyond have an essential role to play in widely disseminating and discussing human sexualities needs, while enhancing health equity for MSM and other sexual minorities.

\section{Acknowledgements}

The authors would like to thank the International AIDS Vaccine Initiative for supporting our work at the 
KEMRI-Wellcome Trust Research Programme in Kilifi. The KWTRP at the Centre for Geographical Medicine Research-Kilifi is supported by core funding from the Wellcome Trust (\#077092). Research with MSM in Coastal Kenya is made possible by the generous support of the American people through the United States Agency for International Development (USAID). Research is also supported by the University of Washington Center for AIDS Research (CFAR), an NIH-funded programme (P30 AI027757), which is supported by the following NIH institutes and centres (NIAID, NCI, NIMH, NIDA, NICHD, NHLBI, and NCCAM).

DO's involvement in this project was supported in part by NIH grants NIAAA P01AA019072, and R24HD077976, and SMG was supported by NIH grant 1R34MH099946-01.

The contents of the viewpoint are the responsibility of the study authors and do not necessarily reflect the views of USAID, the NIH, the United States Government, the Wellcome Trust, the Ministry of Health or KEMRI. This report was published with permission from KEMRI.

\section{Conflicts of interest}

There are no conflicts of interest.

\section{References}

1. Pantelic M, Shenderovich Y, Cluver L, Boyes M. Predictors of internalised HIV-related stigma: a systematic review of studies in sub-Saharan Africa. Health Psychol Rev 2015:1-22 [Epub ahead of print].

2. Smith AD. Men who have sex with men and HIV transmission risks in sub-Saharan Africa: a Kenyan case Study [DPhil. thesis]. Oxford: St Catherine's College, University of Oxford; 2013. pp. $44-60$

3. Sanders EJ, Okuku HS, Smith AD, Mwangome M, Wahome E, Fegan G, et al. High HIV-1 incidence, correlates of HIV-1 acquisition, and high viral loads following seroconversion among MSM. AIDS 2013; 27:437-446.

4. Tanser $F$, de Oliveira T, Maheu-Giroux M, Barnighausen T. Concentrated HIV subepidemics in generalized epidemic settings. Curr Opin HIV AIDS 2014; 9:115-125.

5. Beyrer C. Strategies to manage the HIV epidemic in gay, bisexual, and other men who have sex with men. Curr Opin Infect Dis 2014; 27:1-8.

6. Viola LUoT. Homophobia and homosexual desire in Kenya. In: ECAS 5th European Conference on African Studies African dynamics in a multipolar world. Lisbon; 2013.

7. Adam PC, de Wit JB, Toskin I, Mathers BM, Nashkhoev M, Zablotska I, et al. Estimating levels of HIV testing, HIV prevention coverage, HIV knowledge, and condom use among men who have sex with men (MSM) in low-income and middleincome countries. J Acquir Immune Defic Syndr 2009; 52 (Suppl 2):S143-151.

8. Muraguri N, Tun W, Okal J, Broz D, Raymond HF, Kellogg $\mathrm{T}$, et al. HIV and STI prevalence and risk factors among male sex workers and other men who have sex with men in Nairobi, Kenya. I Acquir Immune Defic Syndr 2015; 68:91-96.

9. Beyrer C, Baral SD, van Griensven F, Goodreau SM, Chariyalertsak S, Wirtz AL, et al. Global epidemiology of HIV infection in men who have sex with men. Lancet 2012; 380:367-377.
10. Muraguri N, Temmerman M, Geibel S. A decade of research involving men who have sex with men in Sub-Saharan Africa: current knowledge and future directions. SAHARA / 2012; 9:137-147.

11. Smith AD, Tapsoba P, Peshu N, Sanders EJ, Jaffe HW. Men who have sex with men and HIV/AIDS in sub-Saharan Africa. Lancet 2009; 374:416-422.

12. Fay H, Baral SD, Trapence G, Motimedi F, Umar E, lipinge S, et al. Stigma, healthcare access, and HIV knowledge among men who have sex with men in Malawi, Namibia, and Botswana. AIDS Behav 2011; 15:1088-1097.

13. Kennedy CE, Baral SD, Fielding-Miller R, Adams D, Dludlu P, Sithole $B$, et al. They are human beings, they are Swazi: intersecting stigmas and the positive health, dignity and prevention needs of HIV-positive men who have sex with men in Swaziland. J Int AIDS Soc 2013; 16 (Suppl 3):18749.

14. Nordling L. Homophobia and HIV research: under siege. Nature 2014; 509:274-275.

15. Messerschmidt L. Technical support delivery and KAP engagement in the cameroonian global fund process. In: Global Fund's New Funding Model (NFM), Global Fund's New Funding Model (NFM). Edited by Technical Assistance Program on Community RaG. Cameroon: MSMGF; 2015.

16. Risher K, Adams D, Sithole B, Ketende S, Kennedy C, Mnisi Z, et al. Sexual stigma and discrimination as barriers to seeking appropriate healthcare among men who have sex with men in Swaziland. J Int AIDS Soc 2013; 16:18715.

17. van der Elst EM, Smith AD, Gichuru E, Wahome E, Musyoki $\mathrm{H}$ Muraguri $\mathrm{N}$, et al. Men who have sex with men sensitivity training reduces homoprejudice and increases knowledge among Kenyan healthcare providers in coastal Kenya. J Int AIDS SOC 2013; 16:18748.

18. King R, Barker J, Nakayiwa S, Katuntu D, Lubwama G, Bagenda $D$, et al. Men at risk; a qualitative study on HIV risk, gender identity and violence among men who have sex with men who report high risk behavior in Kampala, Uganda. PLoS One 2013; 8:e82937.

19. Okall DO, Ondenge K, Nyambura M, Otieno FO, Hardnett F, Turner K, et al. Men who have sex with men in Kisumu, Kenya: comfort in accessing health services and willingness to participate in HIV prevention studies. J Homosex 2014; 61:1712-1726.

20. Taegtmeyer M, Davies A, Mwangome M, van der Elst EM, Graham SM, Price MA, et al. Challenges in providing counselling to MSM in highly stigmatized contexts: results of a qualitative study from Kenya. PLoS One 2013; 8:e64527.

21. Dijkstra M, van der Elst EM, Micheni M, Gichuru E, Musyoki H, Duby $Z$, et al. Emerging themes for sensitivity training modules of African healthcare workers attending to men who have sex with men: a systematic review. Int Health 2015; 7:151-162.

22. Mutua G, Sanders E, Mugo P, Anzala O, Haberer JE, Bangsberg $\mathrm{D}$, et al. Safety and adherence to intermittent preexposure prophylaxis (PrEP) for HIV-1 in African men who have sex with men and female sex workers. PLOS One 2012; 7:e33103.

23. Graham SM, Mugo P, Gichuru E, Thiong'o A, Macharia M Okuku HS, et al. Adherence to antiretroviral therapy and clinical outcomes among young adults reporting high-risk sexual behavior, including men who have sex with men, in coastal Kenya. AIDS Behav 2013; 17:1255-1265.

24. Okuku HS, Sanders EJ, Nyiro J, Ngetsa C, Ohuma E, McClelland $\mathrm{RS}$, et al. Factors associated with herpes simplex virus type 2 incidence in a cohort of human immunodeficiency virus type 1seronegative Kenyan men and women reporting high-risk sexual behavior. Sex Transm Dis 2011; 38:837-844.

25. Sanders EJ, Wahome E, Okuku HS, Thiong'o AN, Smith AD, Duncan $S$, et al. Evaluation of WHO screening algorithm for the presumptive treatment of asymptomatic rectal gonorrhoea and chlamydia infections in at-risk MSM in Kenya. Sex Transm Infect 2013; 90:92-99.

26. Neme S, Wahome E, Mwashigadi G, Thiong'o AN, Stekler JD, Wald $A$, et al. Prevalence, incidence, and clearance of anogenital warts in Kenyan men reporting high-risk sexual behavior, including men who have sex with men. Open Forum Infect Dis 2015; 2:ofv070.

27. van der Elst EM, Gichuru E, Omar A, Kanungi J, Duby Z, Midoun $M$, et al. Experiences of Kenyan healthcare workers providing services to men who have sex with men: qualitative findings from a sensitivity training programme. I Int AIDS SOC 2013; 16:18741. 
28. NACC. Kenya HIV Prevention Response and Modes of Transmission Analysis. Final report. In. Edited by Council NAC. Nairobi, Kenya; 2009. http:siteresources.worldbank.org/INTHI VAIDS/Resources/375798-1103037153392/kenyaMOT22 March09Final.pdf. [Accessed 8 April 2015]

29. NACC. Kenya AIDS Strategic Framework 2014/2015-2018/ 2019 (KNASF IV); 2014.

30. NACC, NASCOP. Kenya HIV Prevention Revolution Road Map, Countdown to 2030. Edited by Kenya MoHo. Nairobi, Kenya: NACC and NASCOP; 2014.
31. WHO. HIV prevention urgently needed for MSM and transgender people. http://www.towleroad.com/2014/07/world-healthorganization-endorses-prep-for-all-men-having-sex-with-men. html; 2014. [Accessed 20 April 2015]

32. Grant RM, Lama JR, Anderson PL, McMahan V, Liu AY, Vargas L, et al. Preexposure chemoprophylaxis for HIV prevention in men who have sex with men. N Engl J Med 2010; 363:2587-2599.

33. Le T, Wright El, Smith DM, He W, Catano G, Okulicz JF, et al. Enhanced CD4+ T-cell recovery with earlier HIV-1 antiretroviral therapy. N Engl / Med 2013; 368:218-230. 